\title{
ESTUDO DE METAIS E DE SUBSTÂNCIAS TÓXICAS EM BRINQUEDOS
}

Josiane Zini, João C. Ferreira*, Fátima M. S. de Carvalho, José O. W.V. Bustillos, Marcos A. Scapin, Vera L. R Salvador e Alcídio Abrão

Centro de Química e Meio Ambiente, Instituto de Pesquisas Energéticas Nucleares, Av Prof, Lineu Prestes, 2242, Cidade Universitária, 05508-900 São Paulo - SP, Brasil

Recebido em 20/8/07; aceito em 4/11/08; publicado na web em 25/3/09

\begin{abstract}
TOYS CONTAMINED BY TOXIC SUBSTANCES. The main goal of the present study is the analysis of toxic elements in plastic toys commercialized in Brazil. Metals like cadmium, lead, chromium, zinc, and aluminum, along with organic substances, such as phthalates, were identified in different toys by quantitative analytical techniques. Traces of thorium were detected in one of the studied samples. Although the measured radioactive dose was rather low, the presence of such a radioactive contaminant is against to the International Agency of Atomic Energy regulations. Similar toys manufactured in Brazil were analyzed and found to observe the standards defined by the National Institute of Metrology (Inmetro).
\end{abstract}

Keywords: toys; toxic elements; heavy metals.

\section{INTRODUÇÃO}

Neste trabalho faz-se um alerta de que brinquedos de plásticos, provenientes de países asiáticos e utilizados normalmente por crianças, contêm quantidades de substâncias perigosas à saúde as quais, segundo trabalho prévio, ${ }^{1}$ se encontram acima do limite permitido pelo Inmetro. ${ }^{2}$ Além de metais como cádmio, chumbo, cromo, mercúrio, alumínio, cobre e tório, foram detectados altos teores de ftalatos, substâncias adicionadas ao plástico para fornecer flexibilidade a este material.

Há algum tempo pesquisadores estudam os danos que podem ser causados pelo uso prolongado de utensílios plásticos que contenham ftalatos em suas composições, como copos, pratos, garrafões para água mineral e mamadeiras, que podem causar sérios danos à saúde, afetando principalmente a fertilidade e a capacidade reprodutiva. ${ }^{3,4}$

Elementos tóxicos como arsênico, cádmio, cromo, níquel e antimônio assim como elementos não tóxicos como bário, cálcio, cobalto, ferro, escândio, selênio e zinco já foram encontrados em amostras de embalagens plásticas metalizadas. ${ }^{5}$ Os autores deste trabalho, em estudos anteriores, identificaram elementos tóxicos em amostras de bonecas de PVC e látex, como chumbo, cromo e cádmio, em teores significativos. $^{1}$

Com relação a estes elementos pode-se citar que a ingestão de chumbo pode levar a distúrbios de comportamento, dificuldade de concentração e de aprendizado e, em casos graves, contamina o sistema nervoso, a medula óssea e os rins. O risco é maior para crianças e para gestantes, pois o chumbo interfere nos processos genéticos ou cromossômicos e produz alterações na estabilidade da cromatina, como comprovado em cobaias, inibindo reparo de DNA e agindo como agente cancerígeno. ${ }^{5}$ Os compostos de cromo, por sua vez, produzem reações cutâneas, nasais, bronco-pulmonares, renais, gastrointestinais e carcinogênicas. As cutâneas são caracterizadas por irritação no dorso das mãos e dos dedos, podendo transformar-se em úlceras. As lesões nasais iniciam-se com um quadro irritativo inflamatório, supuração e formação crostosa. Em níveis bronco-pulmonares e gastrointestinais, produzem irritação bronquial, alteração da função respiratória e úlceras gastroduodenais. ${ }^{1}$ Já o cádmio, mesmo em doses

*e-mail: jcferrei@ipen.br mínimas, provoca envenenamento grave e prolongado ocasionando, também, danos nos ossos, pulmões e sangue. ${ }^{6}$

Presentes em brinquedos, tais elementos químicos em doses perigosas podem ser ingeridos por crianças com idade prematura, entre 0 a 5 anos. A Comissão de Segurança de Produtos para o Consumidor dos Estados Unidos demonstrou experimentalmente que a luz e o calor podem causar a degradação do polivinil, ocorrendo liberação de poeira de chumbo e cádmio. ${ }^{7}$

Os ftalatos são substâncias empregadas como "plastificantes" para tornar o PVC (cloreto de polivinila ou "vinil") mais flexível, sendo componentes de produtos como brinquedos, mordedores, forros, pisos, vestimentas (capas de chuva, botas, casacos tipo couro, etc.), papel de parede e produtos cirúrgicos (bolsas de sangue, cateteres etc.). Nos produtos cosméticos permitem aos óleos uma película "umectante" e auxiliam a dissolver e fixar outros ingredientes. São também empregados como solventes em perfumes e para a desnaturação do álcool nos cosméticos. ${ }^{8,9}$

Os ftalatos causam uma série de problemas adversos à saúde, incluindo danos ao fígado, aos rins e pulmões, bem como anormalidades no sistema reprodutivo e ao desenvolvimento sexual, sendo classificados como prováveis carcinogênicos humanos. ${ }^{10}$ Atribuemse à presença de ftalatos, no organismo humano, o dano testicular e possíveis efeitos como a infertilidade..$^{10} \mathrm{Na}$ Figura 1 apresenta-se a estrutura do dibutilftalato, principal substância identificada nas amostras estudadas, que pode causar efeitos irreversíveis muito graves por inalação, em contato com a pele e por ingestão, como cancro e dermatites. ${ }^{11} \mathrm{Na}$ literatura, estudos realizados em ratos e camundongos demonstraram a ocorrência de hiperplasia e hipertrofia hepática, caracterizadas pela proliferação de peroxissomos. A atrofia testicular e a incidência de tumores hepáticos foram um dos efeitos mais evidentes associados à exposição aos ftalatos em uma variedade de espécies animais. ${ }^{12}$

Já em crianças a ingestão destas substâncias pode ser crítica, tanto que o Comitê Econômico e Social da Comunidade Européia e do Parlamento Europeu resolveram proibir seis ftalatos tóxicos em artigos destinados a bebês e a crianças de tenra idade, que constituem o mais frágil e vulnerável grupo de consumidores. ${ }^{13}$ Devido à sua estrutura e à sua lipossolubilidade, os ftalatos são migrantes potenciais e podem ser absorvidos mais facilmente pelo organismo. ${ }^{13,14}$ 


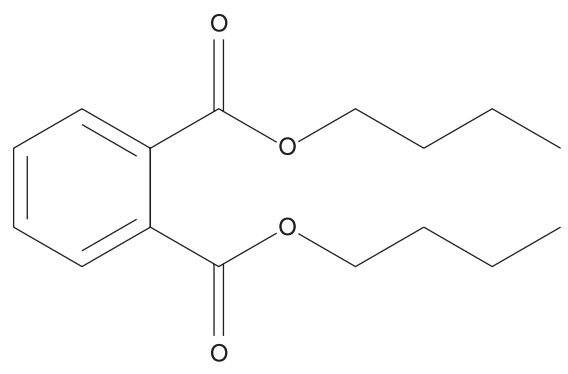

Figura 1. Estrutura do Dibutilftalato(DBP)

Por este motivo, algumas indústrias brasileiras, com apoio da Associação Brasileira dos Fabricantes de Brinquedos e dos Institutos do PVC e da Qualidade do Brinquedo começaram a abolir voluntariamente, em 2001, o uso dos plastificantes ftalatos em brinquedos e mordedores, entre muitos outros itens fabricados em PVC flexível destinados à primeira infância, ou seja, para a faixa etária compreendida entre o nascimento dos bebês e seus 36 meses de vida. ${ }^{15}$

A presença de grandes quantidades de metais nos plásticos pode ser associada aos programas de reciclagem nos países asiáticos, os quais utilizam resíduos provenientes de incineração. Este não é um processo ambientalmente favorável, principalmente por provocar altos índices de poluição, emitindo gases tóxicos e cancerígenos, como cloreto de hidrogênio (que chega a corroer os metais do incinerador), óxido de nitrogênio (que causa chuva ácida) e furanos e dioxinas policlorados (PCDDFs) (que causam alterações hormonais no organismo, podendo causar câncer).$^{16}$

Utilizaram-se neste estudo amostras de bichinhos e bonecos plásticos de fácil aquisição e baixo custo. O objetivo deste trabalho é mostrar os riscos à saúde aos quais a população, principalmente bebês e crianças de famílias de baixa renda, está exposta ao comprar tais produtos.

\section{PARTE EXPERIMENTAL}

\section{Amostragem}

As amostras dos plásticos (bichinhos e bonecos) utilizados neste trabalho provêm de brinquedos comercializados por camelôs na região da fronteira Brasil-Paraguai e no comércio popular de São Paulo. As amostras foram analisadas aleatoriamente, dentre as várias encontradas em um só lote de compra.

\section{Procedimentos analíticos}

Para a caracterização do tipo de plástico utilizado na fabricação dos brinquedos, uma vez que esta informação não estava presente nas embalagens, desconsiderando a norma do Inmetro, foi utilizada a espectrometria de infravermelho.

Nas análises de substâncias orgânicas, os ftalatos, empregou-se a técnica de cromatografia a gás acoplada à espectrometria de massa. ${ }^{17,18}$ Utilizou-se um cromatógrafo a gás com injetor split/splitless com os seguintes parâmetros: temperatura de $250{ }^{\circ} \mathrm{C}$, fluxo total $=$ $5 \mathrm{~mL} / \mathrm{min}$, gás de arraste $=$ hélio, coluna: $\mathrm{DB}-5$, comprimento $=30$ $\mathrm{m}$, temperatura da linha de transferência $250^{\circ} \mathrm{C}$. A programação da coluna foi a seguinte: temperatura inicial $75^{\circ} \mathrm{C}$ mantida durante 4 min; aquecimento a $15{ }^{\circ} \mathrm{C}$ por minuto até $200{ }^{\circ} \mathrm{C}$, mantida durante $8 \mathrm{~min}$. Aquecimento a $20^{\circ} \mathrm{C}$ por minuto até $250{ }^{\circ} \mathrm{C}$, com isoterma final de 2 min. O tempo de retenção do dibutilftalato foi igual a 20,7 min. Os parâmetros de espectrometria de massa foram: ionização por elétrons $(70 \mathrm{eV})$, varredura $(\mathrm{m} / \mathrm{z}=50$ até 250$)$. Foi usado analisador quadrupolo e o equipamento foi um cromatográfo a gás acoplado a espectrômetro de massas tipo quadrupolo (GC/MS Shimatzu. Modelo QP-5000).

As análises qualitativas e quantitativas dos elementos químicos foram realizadas por espectrometria de fluorescência de raios X, ativação com nêutrons e espectrometria gama. Em todas, foram analisados pedaços plásticos recortados dos brinquedos e, também, os óxidos obtidos por calcinação, a partir dos bonecos plásticos.

A fluorescência de raios X por dispersão de energia (EDXRF) está fundamentada na emissão atômica e no efeito fotoelétrico. Uma das vantagens desta técnica é ser não destrutiva, ou seja, pode ser realizada diretamente sobre o material de interesse. Utilizou-se para estas análises o equipamento EDX - 720 da Shimadzu, tubo de raios $\mathrm{X}: \mathrm{Rh}$, detector: $\mathrm{Si}(\mathrm{Li})$ refrigerado com nitrogênio líquido, tensão: 50 $\mathrm{keV}$, corrente: $100 \mu \mathrm{A}$, atmosfera: vácuo, tempo de análise: $60 \mathrm{~s}$.

As análises utilizando a técnica de ativação com nêutrons e a espectrometria gama, foram realizadas no laboratório de Análise por Ativação Neutrônica do IPEN/CNEN-SP. ${ }^{4} \mathrm{O}$ método de análise de ativação com nêutrons consistiu na análise direta das amostras, isto é, irradiando-se os próprios plásticos, com massas variando de 120 a $200 \mathrm{mg}$. Irradiaram-se padrões sintéticos dos elementos sob um fluxo nêutrons térmicos de $3 \times 10^{12} \mathrm{n} \mathrm{cm}^{-2} \mathrm{~s}^{-1}$ por 6 e $16 \mathrm{~h}$ (irradiações realizadas no reator nuclear IEA-R1 do IPEN/CNEN-SP). Após 4 dias de decaimento, fizeram-se as medições das atividades gama induzidas nas amostras e nos padrões usando-se um detector de Ge hiperpuro acoplado a um espectrômetro de raios gama. Calcularam-se as concentrações dos elementos pelo método comparativo de análise por ativação. Calcularam-se os valores dos limites de detecção pelo critério de Curie. Para as análises por espectrometria gama direta (sem tratamento de irradiação), do plástico dos bonecos e seus óxidos foi utilizado o mesmo detector de Ge hiperpuro acoplado a um espectrômetro de raios gama.

Os teores dos elementos químicos encontrados foram comparados com os limites máximos permitidos de cada um, segundo a norma NBR 11786/98 do Inmetro. Na Tabela 1 são apresentados os elementos e seus respectivos limites máximos permitidos em brinquedos plásticos.

Tabela 1. Concentração máxima permitida de metais pesados em plásticos de brinquedos (Norma NBR11786/98 - Inmetro)

\begin{tabular}{lc}
\hline Elemento & Concentração máxima $\left(\mathrm{mg} \mathrm{kg}^{-1}\right)$ \\
\hline $\mathrm{Sb}$ & 60 \\
$\mathrm{As}$ & 25 \\
$\mathrm{Ba}$ & 1000 \\
$\mathrm{Cd}$ & 75 \\
$\mathrm{~Pb}$ & 90 \\
$\mathrm{Cr}$ & 60 \\
$\mathrm{Hg}$ & 60 \\
$\mathrm{Se}$ & 500 \\
\hline
\end{tabular}

\section{RESULTADOS E DISCUSSÃO}

\section{Caracterização das amostras}

Recortaram-se pedaços de bichinhos fluorescentes, peixinhos, bonecos Hello Kitty e bonecos com formato de frutas. Foram pesados, queimados e calcinados à temperatura de $800^{\circ} \mathrm{C}$ até peso constante, para posterior análise. Nas Figuras de 2 a 5 apresenta-se o tipo de brinquedos utilizados para os estudos deste trabalho. 


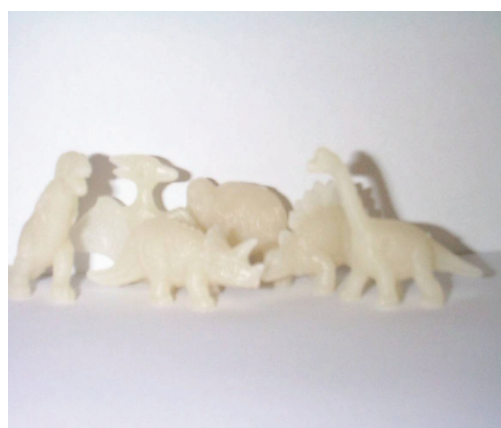

Figura 2. Amostras dos bichinhos fluorescentes

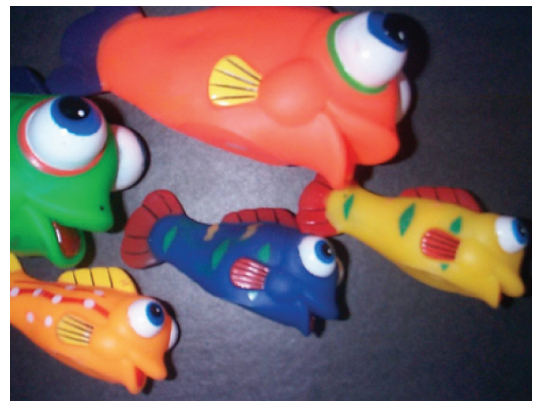

Figura 3. Amostras dos peixinhos

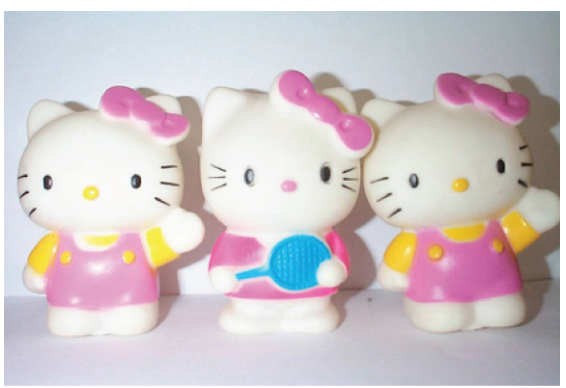

Figura 4. Amostras dos bonecos Hello Kitty

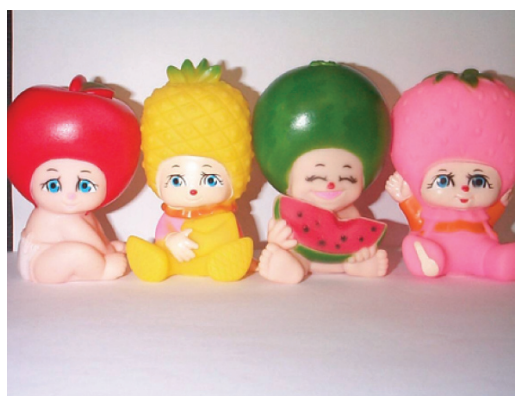

Figura 5. Amostras dos bonecos com formato de frutas

\section{Análise por espectrometria de infravermelho}

Foram feitos filmes ultrafinos dos plásticos de cada brinquedo, através do corte e prensa a alta temperatura. As análises dos plásticos de todos os brinquedos utilizados neste trabalho deram resultados semelhantes ao apresentado na Figura 6. O gráfico demonstra que o material utilizado na fabricação destes brinquedos foi o PVC. ${ }^{19}$

\section{Determinação dos elementos químicos por espectrometria gama}

As amostras do bichinho fluorescente não puderam ser analisadas diretamente sobre o plástico por espectrometria gama, como ocorreu com os peixinhos, pois não apresentaram sinal suficiente. Isto se deve ao fato de os metais estarem dispersos na matriz orgânica, sendo ne-

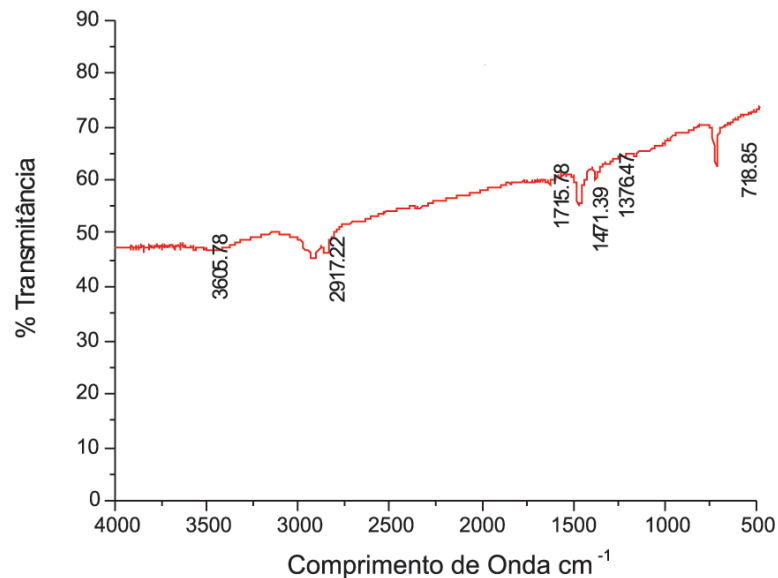

Figura 6. Espectro infravermelho do plástico do boneco

cessária uma grande quantidade de amostra para a análise, o que não é adequado ao equipamento. Assim sendo, queimaram-se os bichinhos fluorescentes em cadinho e posteriormente a matriz orgânica foi destruída por calcinação, concentrando-se, desta forma, os metais na forma de óxidos e efetivando-se a medida no espectrômetro gama.

Resultados da análise por espectrometria gama no óxido obtido pela calcinação dos plásticos dos bichinhos fluorescentes

Foram identificados o isótopo ${ }^{40} \mathrm{~K}$, isótopo natural e alguns isótopos das séries radioativas do $\mathrm{U}$ e $\mathrm{Th}$, entre eles ${ }^{212} \mathrm{~Pb},{ }^{212} \mathrm{Bi},{ }^{228} \mathrm{Ac}$, ${ }^{208} \mathrm{Tl},{ }^{226} \mathrm{Ra}$ e ${ }^{214} \mathrm{Bi}$.

\section{Resultados da análise por espectrometria gama realizada} diretamente em pedaços plásticos dos peixinhos

Foram identificados alguns isótopos descendentes do urânio e do tório, entre eles ${ }^{212} \mathrm{~Pb},{ }^{228} \mathrm{Ac},{ }^{208} \mathrm{Tl},{ }^{214} \mathrm{~Pb}$ e ${ }^{214} \mathrm{Bi}$.

\section{Análise por ativação neutrônica}

Foram analisadas por este método amostras de plástico do peixinho e do bichinho fluorescente. Determinaram-se, por ativação com nêutrons (NAA), os teores de alguns metais e também de tório nestes plásticos.

$\mathrm{Na}$ análise direta do plástico em uma das amostras do peixinho encontraram-se $40 \pm 2 \mathrm{ng} / \mathrm{g}$ de $\mathrm{Th}$, um elemento químico radioativo que, mesmo presente em baixíssima quantidade, não é permissível de acordo com normas da Comissão Nacional de Energia Nuclear e da Agência Internacional de Energia Atômica. ${ }^{20}$

Por meio destas análises verificou-se que em algumas amostras dos peixinhos não há tório, entretanto em outras este elemento foi identificado, embora não homogeneamente, ou seja, em um determinado peixinho o tório se encontrava próximo aos olhos do brinquedo e no resto do corpo do brinquedo não se detectava a presença deste elemento. Os valores para outros metais encontram-se na Tabela 2 (valores apresentados em mg de metal presente em $1 \mathrm{~kg}$ de plástico).

De acordo com os resultados mostrados na Tabela 2, observa-se que o teor de cádmio nos bichinhos fluorescentes se encontra acima do valor permitido pelo Inmetro e o teor de zinco na mesma amostra, mesmo não sendo especificada por este Instituto, é bastante significativa.

\section{Análise por espectrometria de fluorescência de raios $\mathbf{X}$ diretamente sob o plástico do peixinho}

Na Tabela 3 apresentam-se os resultados por este método. 
Tabela 2. Resultados obtidos por ativação neutrônica $\left(\mathrm{mg} \mathrm{kg}^{-1}\right)$ dos peixinhos e bichinhos fluorescentes

\begin{tabular}{lcc}
\hline Elemento & Peixinhos $\left(\mathrm{mg} \mathrm{kg}^{-1}\right)$ & Bichinhos fluorescentes $\left(\mathrm{mg} \mathrm{kg}^{-1}\right)$ \\
\hline $\mathrm{As}$ & $<0,05$ & $<0,05$ \\
$\mathrm{Ba}$ & $22 \pm 3$ & $651 \pm 41$ \\
$\mathrm{Br}$ & $2,0 \pm 0,1$ & $9,5 \pm 0,1$ \\
$\mathrm{Cd}$ & $<0,2$ & $81 \pm 6$ \\
$\mathrm{Cr}$ & $0,4 \pm 0,1$ & $<0,1$ \\
$\mathrm{Mo}$ & $0,5 \pm 0,1$ & $<0,1$ \\
$\mathrm{Sb}$ & $0,6 \pm 0,1$ & $0,6 \pm 0,1$ \\
$\mathrm{Zn}$ & $80 \pm 4$ & $22626 \pm 887$ \\
\hline
\end{tabular}

Tabela 3. Análise elementar diretamente no plástico do peixinho por fluorescência de raios X

\begin{tabular}{lc}
\hline Elemento & Valor encontrado $\left(\mathrm{mg} \mathrm{kg}^{-1}\right)$ \\
\hline $\mathrm{Pb}$ & $7,5 \pm 0,8$ \\
$\mathrm{Th}$ & $6,0 \pm 0,6$ \\
$\mathrm{Ca}$ & $19500 \pm 975$ \\
$\mathrm{~S}$ & $1795 \pm 90$ \\
$\mathrm{~K}$ & $769 \pm 76$ \\
$\mathrm{Ti}$ & $513 \pm 50$ \\
$\mathrm{Zn}$ & $50 \pm 5$ \\
$\mathrm{Cu}$ & $42 \pm 4$ \\
\hline
\end{tabular}

A análise por fluorescência de raios $\mathrm{X}$, diretamente no plástico do peixinho, também detectou uma pequena quantidade de tório, confirmando assim a presença deste elemento no referido brinquedo.

Análises por espectrometria de fluorescência de raios $\mathbf{X}$ nos óxidos obtidos a partir da calcinação dos plásticos dos brinquedos

Essas amostras foram analisadas, após a calcinação a 800 ${ }^{\circ} \mathrm{C}$ dos plásticos dos brinquedos, na forma de pastilha prensada por fluorescência de raios $\mathrm{X}$ utilizando o sistema de dispersão de comprimento de onda WDXRF Rigaku. ${ }^{21}$ Esse sistema permite detectar elementos químicos de $\mathrm{Z}=11$ (sódio) a $\mathrm{Z}=92$ (urânio) em concentrações de $\mathrm{mg}$ por $\mathrm{g}$ em diversos tipos de matrizes, porem com maior sensibilidade principalmente para os elementos leves $(Z<22)$ e erro relativo percentual inferior a $3 \% .{ }^{22}$ Os valores apresentados nos resultados são expressos em mg de metal por kg de plástico, a fim de facilitar a comparação com os valores máximos permitidos pela norma NBR11786/98 do Inmetro.

$\mathrm{O}$ cálculo da incerteza de medição utilizada para o método de análise por fluorêscencia de raios X seguiu as normas da Abnt/ Inmetro. $^{23}$

\section{Peixinhos}

Apresenta-se na Tabela 4 a análise elementar dos peixinhos, obtida por fluorescência de raios $\mathrm{X}$, a partir dos óxidos obtidos pela incineração do plástico.

Os valores dos elementos tório e bário indicados na Tabela 4 não estão dentro da norma do Inmetro. O material plástico incinerado mostrou que o processo de incineração permite analisar teores
Tabela 4. Análise elementar nas cinzas do peixinho por fluorescência de raios $\mathrm{X}$

\begin{tabular}{lc}
\hline Elemento & Valor encontrado $\left(\mathrm{mg} \mathrm{kg}^{-1}\right)$ \\
\hline $\mathrm{Ca}$ & $99590 \pm 4980$ \\
$\mathrm{Ti}$ & $48682 \pm 2434$ \\
$\mathrm{~S}$ & $7722 \pm 386$ \\
$\mathrm{Si}$ & $8008 \pm 400$ \\
$\mathrm{Th}$ & $5924 \pm 296$ \\
$\mathrm{Ba}$ & $4391 \pm 220$ \\
$\mathrm{Al}$ & $2271 \pm 114$ \\
$\mathrm{Cl}$ & $4290 \pm 215$ \\
$\mathrm{P}$ & $11640 \pm 582$ \\
$\mathrm{Zn}$ & $344 \pm 35$ \\
$\mathrm{Fe}$ & $985 \pm 100$ \\
\hline
\end{tabular}

metálicos já perigosos à população, inclusive o tório, cuja presença em maior quantidade permite a identificação de sua radioatividade com segurança.

\section{Bichinhos fluorescentes}

Na Tabela 5 apresentam-se os resultados de análise dos bichinhos fluorescentes depois de calcinados.

Tabela 5. Análise elementar diretamente no plástico do bichinho fluorescente por fluorescência de raios X

\begin{tabular}{lc}
\hline Elemento & Valor encontrado $\left(\mathrm{mg} \mathrm{kg}^{-1}\right)$ \\
\hline $\mathrm{Cl}$ & $33000 \pm 1650$ \\
$\mathrm{Zn}$ & $9851 \pm 490$ \\
$\mathrm{Mg}$ & $6937 \pm 350$ \\
$\mathrm{Si}$ & $5799 \pm 350$ \\
$\mathrm{Na}$ & $966 \pm 100$ \\
$\mathrm{~S}$ & $910 \pm 90$ \\
$\mathrm{~K}$ & $423 \pm 40$ \\
$\mathrm{Al}$ & $398 \pm 40$ \\
$\mathrm{~Pb}$ & $376 \pm 40$ \\
$\mathrm{Ca}$ & $205 \pm 20$ \\
$\mathrm{P}$ & $190 \pm 20$ \\
$\mathrm{Fe}$ & $108 \pm 10$ \\
$\mathrm{Ni}$ & $35 \pm 5$ \\
$\mathrm{Cd}$ & $<30$ \\
$\mathrm{Sn}$ & $<30$ \\
\hline
\end{tabular}

Apesar de encontrar neste experimento o cádmio, a quantidade está bem abaixo dos padrões especificados pelo Inmetro, enquanto que o chumbo se apresenta um valor acima do permitido.

\section{Bonecos Hello Kitty}

Na Tabela 6 apresentam-se os resultados da análise elementar nas cinzas das amostras do boneco Hello Kitty por fluorescência de raios X.

Os elementos analisados no boneco Hello Kity não estão espe- 
Tabela 6. Análise elementar por fluorescência de raios X nas cinzas do boneco Hello Kitty

\begin{tabular}{lc}
\hline Elemento & Valor encontrado $\left(\mathrm{mg} \mathrm{kg}^{-1}\right)$ \\
\hline $\mathrm{Cl}$ & $116199 \pm 5809$ \\
$\mathrm{Ca}$ & $55406 \pm 2770$ \\
$\mathrm{Na}$ & $1008 \pm 50$ \\
$\mathrm{~S}$ & $565 \pm 57$ \\
$\mathrm{Mg}$ & $564 \pm 57$ \\
$\mathrm{Si}$ & $523 \pm 50$ \\
$\mathrm{Zn}$ & $342 \pm 35$ \\
$\mathrm{Al}$ & $303 \pm 30$ \\
$\mathrm{Ti}$ & $267 \pm 27$ \\
$\mathrm{~K}$ & $185 \pm 20$ \\
$\mathrm{Fe}$ & $95 \pm 10$ \\
$\mathrm{P}$ & $53 \pm 5$ \\
$\mathrm{Ni}$ & $19 \pm 2$ \\
$\mathrm{Sr}$ & $14 \pm 1$ \\
\hline
\end{tabular}

cificados na tabela do Inmetro, mas pode-se notar que os valores encontrados são elevados.

\section{Bonecos com formato de frutas}

Na Tabela 7 encontram-se os resultados da análise dos elementos nas cinzas das amostras do boneco por fluorescência de raios X. Nesta Tabela verifica-se que os bonecos com formato de frutas apresentam valores elevados de alguns metais não especificados pela norma do Inmetro. O chumbo, com valor acima da norma do Inmetro, foi encontrado em apenas um dos bonecos.

\section{Análise por cromatografia a gás e espectrometria de massas}

Pedaços plásticos dos brinquedos foram mantidos em um sistema fechado a vácuo e as substâncias voláteis foram retidas em adsorventes. Em seguida, foi feita a extração das substâncias com n-octano e então analisadas por um cromatógrafo a gás acoplado a um espectrômetro de massas.

Analisaram-se os plásticos dos peixinhos, bichinhos fluorescentes, bonecos Hello Kitty e bonecos com formato de frutas. Os resultados foram iguais para todas as amostras, com tempo de retenção de 20,7 min. Na Figura 7 apresenta-se o cromatograma obtido das amostras e o espectro de massa do dibutilftalato, substância separada e identificada nas análises por GC-MS.

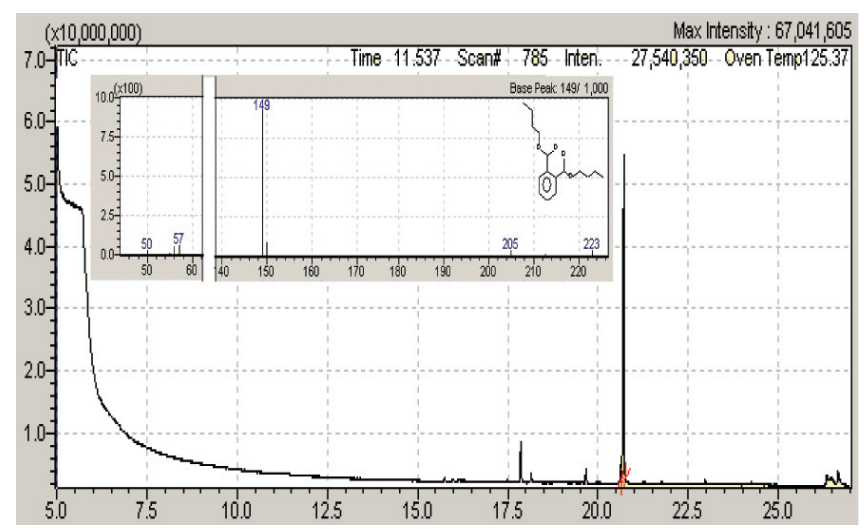

Figura 7. Cromatograma do extrato do boneco com formato de maçã e o espectro de massa do dibutilftalato

\section{CONCLUSÃO}

Utilizaram-se as técnicas de fluorescência de raios X e análise por ativação neutrônica para se identificar e quantificar os elementos

Tabela 7. Análise elementar por fluorescência de raios X nas cinzas do plástico dos bonecos com formato de frutas

\begin{tabular}{|c|c|c|c|c|}
\hline Elemento & $\operatorname{Maçã~}\left(\mathrm{mg} \mathrm{kg}^{-1}\right)$ & Abacaxi $\left(\mathrm{mg} \mathrm{kg}^{-1}\right)$ & Melancia $\left(\mathrm{mg} \mathrm{kg}^{-1}\right)$ & Morango $\left(\mathrm{mg} \mathrm{kg}^{-1}\right)$ \\
\hline $\mathrm{Ti}$ & $174883 \pm 8744$ & $33153 \pm 6273$ & $179729 \pm 8986$ & $61749 \pm 3087$ \\
\hline $\mathrm{P}$ & $19246 \pm 962$ & $125450 \pm 1658$ & $18668 \pm 933$ & $18257 \pm 913$ \\
\hline $\mathrm{Ca}$ & $44928 \pm 2246$ & $81568 \pm 4078$ & $46173 \pm 2309$ & $29612 \pm 1481$ \\
\hline $\mathrm{Si}$ & $18027 \pm 901$ & $41014 \pm 2051$ & $20665 \pm 1033$ & $6164 \pm 308$ \\
\hline $\mathrm{Mg}$ & $12184 \pm 609$ & $28902 \pm 1445$ & $12302 \pm 615$ & $4088 \pm 204$ \\
\hline $\mathrm{Al}$ & $3408 \pm 170$ & $7280 \pm 364$ & $3772 \pm 189$ & $2509 \pm 125$ \\
\hline $\mathrm{Zn}$ & $9152 \pm 458$ & $7685 \pm 384$ & $7361 \pm 368$ & $2870 \pm 144$ \\
\hline $\mathrm{Na}$ & $8320 \pm 416$ & $7452 \pm 373$ & $7815 \pm 391$ & $4991 \pm 250$ \\
\hline $\mathrm{Fe}$ & $1086 \pm 54$ & $2856 \pm 143$ & $1215 \pm 61$ & $652 \pm 65$ \\
\hline K & $935 \pm 94$ & $722 \pm 72$ & $845 \pm 85$ & $885 \pm 89$ \\
\hline $\mathrm{Cl}$ & $346 \pm 35$ & $4065 \pm 203$ & $1221 \pm 61$ & $1108 \pm$ \\
\hline S & $1010 \pm 51$ & $1674 \pm 84$ & $1119 \pm 56$ & $418 \pm 42$ \\
\hline $\mathrm{Cu}$ & $158 \pm 16$ & $143 \pm 14$ & $243 \pm 12$ & $91 \pm 9$ \\
\hline $\mathrm{Mn}$ & $115 \pm 12$ & $277 \pm 28$ & $118 \pm 12$ & $46 \pm 5$ \\
\hline $\mathrm{Ni}$ & $83 \pm 8$ & $46 \pm 5$ & $80 \pm 8$ & $38 \pm 4$ \\
\hline $\mathrm{Zr}$ & - & $44 \pm 4$ & $<37$ & $9 \pm 1$ \\
\hline $\mathrm{Pb}$ & $137 \pm 14$ & - & - & - \\
\hline $\mathrm{Sr}$ & - & $<50$ & $<40$ & - \\
\hline
\end{tabular}


metálicos nos brinquedos plásticos. Usou-se a cromatografia a gás e a espectrometria de massas para análises semiquantitativas dos ftalatos e a espectroscopia por infravermelho para identificação dos plásticos.

Os resultados mostraram que os plásticos dos brinquedos analisados contêm vários metais, sendo alguns prejudiciais à saúde. Identificou-se também, neste trabalho, o elemento tório que, apesar de não estar presente em todas as amostras analisadas, em algumas se encontrava de forma heterogênea. Isso pode ser devido ao uso de materiais recicláveis utilizados na confecção dos brinquedos. O tório é um elemento radioativo e de alta periculosidade à saúde pública, mesmo sendo encontrado em baixa quantidade.

Por espectrometria gama, análise para identificar os isótopos naturais do urânio e tório, encontrou-se o elemento tório em quantidade baixa, o que não permitiu a medida da emissão de dose radioativa, nos peixinhos e bichinhos fluorescentes. Embora não se tenha detectado a presença de urânio, por meio das análises feitas pode-se notar a presença de alguns de seus descendentes.

Os resultados dos metais foram comparados aos valores reconhecidos como perigosos à saúde pelo Inmetro, denominados, usualmente, de "metais pesados". São elementos que não existem naturalmente em qualquer organismo e tampouco desempenham funções nutricionais ou bioquímicas em microorganismos, plantas ou animais, ou seja, a presença destes metais em organismos vivos é prejudicial em concentrações acima do limite máximo permitido pelas legislações pertinentes.

Este trabalho preocupou-se em mostrar, por meio de resultados analíticos, que brinquedos importados de procedência duvidosa, como aqueles que crianças facilmente levam à boca e mordem, estão contaminados com elementos tóxicos e isto deve servir de alerta aos consumidores.

As análises comprovaram, também, que a incineração deste tipo de brinquedo pode ocasionar contaminação ao meio ambiente com elementos tóxicos e mesmo os não tóxicos que, em grande quantidade, são prejudiciais à saúde.

\section{REFERÊNCIAS}

1. Ferreira, J. C.; Zini, J.; Scarpin, M. A.; Carvalho, F. M. S.; Abrão, A.; $3^{\circ}$ Congresso Brasileiro de Gestão Ambiental e Desenvolvimento Sustentável, São Pedro, Brasil, 2006.
2. http://www.inmetro.gov.br/consumidor/produtos/brinquedos2.asp, acessada em Abril 2007.

3. Chiang, K. Y.; Wang, K. S.; Tsai, C. C.; Sun, C. J.; J. Environ. Sci. Health A Tox. Hazard Subst. Environ. Eng. 2001, 36, 833.

4. U. S. Consumer Product Safety Commission; Report on Lead in Vinyl Miniblinds 1996, 19.

5. Soares, E. P.; Nunes, E. C. D.; Saiki, M.; Wiebeck, H.; Polímeros 2002, 12, 206.

6. Baranska-Gachowska, M.; Soja, J.; Postek, L.; Owczarczak, K.; Czas, S.; J. Master List. 1987, 40, 89.

7. Subramanian, P. M.; Resour. Conserv. Recycl. 2000, 28, 253.

8. Tuczai, E.; Cortolano, F.; Modern Plastics 1992, 123.

9. http://www.nossofuturoroubado.com.br/ftalatos.htm, acessada em Maio 2007.

10. Gangi, D. J.; Greenpeace USA, Washington, Estados Unidos, 1999.

11. Euronavy; CA45 Endurecedor. Ficha de Segurança, Mod 60/01, 2004, p. 1.

12. http://www.cdc.gov/nceh/dls/report, acessada em Maio 2007.

13. Comissão das Comunidades Européias; Relatório da Comissão Relatório Anual do Centro Comum de Investigação. 2000, Bruxelas, 07.05.2001, COM. 2001 239, 1.

14. http://eur-lex.europa.eu, acessada em Maio 2007.

15. http://www.plastico.com.br/revista/pm315/aditivos5.htm, acessada em Maio 2007.

16. Lu-shi, S.; Abanades. S.; Lu, J. D.; Flamant. G.; Gauthier, D.; J. Environ. Sci. 2004, 16, 635.

17. Sassine, A.; Moura, S.; Léo, V. M.; Bustillos, O. V.; J. Anal. Toxicol. 2004, 28, 238.

18. Vega, O.; Sassine, A.; A Espectrometria de Massas Quadrupolar, Ed. Scortecci: São Paulo, 2003.

19. Krimm, S.; Folt, V. L.; Shipmann, J. J.; Berens, A. R.; J. Polym. Sci. 1963, $1,2621$.

20. ISSN 0074-1892; International Atomic Energy Agency 1996, 115, 57.

21. Scapin, M A.; Dissertação de Mestrado, Universidade de São Paulo, Brasil, 2003.

22. Scapin, V. O.; Scapin, M. A.; Salvador, V. L. R.; Lima, N. B.; Mitani, S. E.; Samad, R. E.; International Nuclear Atlantic Conference, Rio de Janeiro, Brasil, 2002.

23. Abnt/Inmetro; Guia para Expressão da Incerteza de Medição, $3^{\mathrm{a}}$ ed., Brasil, 2003. 